\title{
Learning to write short stories with self-regulation strategy development (SRSD) and text song
}

\author{
Seni Asiati* ${ }^{*}$ \\ SMP Negeri 266 Jakarta \\ *) Correspondences author: Jl. Cilincing Bakti VI No.29, RT.4/RW.9, Cilincing, Kota Jkt Utara, Daerah Khusus Ibukota \\ Jakarta 14120, Indonesia; e-mail: seniasiati@gmail.com
}

\begin{abstract}
This classroom action research aims to improve the skills of writing short stories in junior high school students with strategies SRSD and song texts. The issues are the focus of study in this research is; Do SRSD and song texts can improve learning students' writing? From the analysis of the data, the conclusions obtained from this research is to increase the ability of students to write short stories with SRSD and text tracks that can be seen from the increasing student learning outcomes. It can be seen from the evidence of quantitative and qualitative evidence. Quantitative evidence: the value of students who achieve KKM 34 students (94\%), student scores less than KKM 2 students (5.5\%). There was an increase of $80.2 \%$ from the first cycle and the second cycle. Qualitative evidence shows: (1) the student is doing the learning beminat (2) students are more daring expression (3) the learning environment more natural and fun. Observation of the students do in school activity. Evidence suggests that learning to write short stories SRSD and text can be used to improve the ability to write short stories.
\end{abstract}

Keywords: Writing, SRSD, Text Songs, Short Story

Article History: Received: 13/03/2017; Revised: 25/04/2017; Accepted: 01/05/2017; Published: 05/05/2017

How to Cite (MLA $7^{\text {th }}$ ): Asiati, Seni. "Learning to write short stories with self-regulation strategy development (SRSD) and text song." Hortatori: Jurnal Pendidikan Bahasa dan Sastra Indonesia 1.1 (2017): 08-14. Print/Online. Copyrights Holder: Asiati, Seni. First Publication: Hortatori Jurnal Pendidikan Bahasa dan Sastra Indonesia (2017).

This work is licensed under a Creative Commons Attribution-ShareAlike 4.0 International License.

\section{Pendahuluan}

Mata pelajaran Bahasa Indonesia dimaksudkan untuk membina dan mengembangkan kepercayaan diri peserta didik sebagai komunikator, pemikir imajinatif, dan warga negara Indonesia yang melek literasi dan informasi. Pembelajaran Bahasa Indonesia bertujuan membina dan mengembangkan pengetahuan dan keterampilan berkomunikasi yang diperlukan peserta didik dalam menempuh pendidikan, dunia kerja, dan lingkungan sosial.

Kalau masa lalu menulis harus dengan pena dan buku maka saat ini menjadi lebih praktis dengan bantuan komputer. Bahkan dapat dilakukan dengan telepon selular yang dimiliki. Apa saja bisa ditulis, hasil pengamatan, hasil pendengarannya, dan sebagainya. Dengan kenyataan di atas, penulis memandang perlunya dilakukan perbaikan terhadap pembelajaran menulis cerpen agar siswa dapat menuangkan gagasan dalam bentuk sebuah cerita pendek. Untuk itu guru perlu menggunakan metode dan model pembelajaran yang lebih variatif dan inovatif.

Penggunaan model Model SRSD digunakan dalam penelitian ini. Model pembelajarn ini dianggap mampu mewakili siswa yang kurang mampu dalam menulis. Selain itu penelitian ini menggunakan teks lagu sebagai umpan dalam menghasilkan cerpen karya siswa. Pemilihan model dan media ini merupakan suatu alternatif sebagai bentuk meningkatkan pemahaman dan kreativitas siswa sehingga hasil belajar bahasa Indoensia khususnya kompetensi dasar menulis cerpen dapat tercapai maksimal. Menulis adalah 
kegiatan menyusun dan mengomunikasikan gagasan dengan medium bahasa yang dilakukan penulis kepada pembaca sehingga terjadi interaksi keduanya demi tercapainya suatu tujuan mengungkapkan bahwa menulis merupakan suatu proses (Semi, 1990). Dari proses tersebut, menulis juga melibatkan berbagai keterampilan menyusun pikiran dan perasaan dengan menggunakan kata-kata dalam bentuk susunan yang tepat.

Model SRSD dikembangkan berdasarkan beberapa penelitian yang dilakukan oleh para guru besar menulis yaitu Steve Graham dan Karen R Harris. Menurut mereka SRSD dianggap paling efektif dalam pembelajaran menulis hingga saat ini (Graham dan Perin, 2007). SRSD (Self-Regulation Strategy Development) adalah model pembelajaran menulis untuk membantu siswa-siswa yang kesulitan menulis. Target SRSD adalah penguasaan maksimal terhadap proses kognitif dalam menyusun komposisi tulisan: penggunaan strategi menulis secara self-regulated, reflektif, dan otonom; pemahaman karakteristik tulisan yang baik; sikap posistif terhadap menulis dan kemampuan diri penulis.

Tahapan SRSD yang dikembangkan dengan menggunakakan teks lagu mencangkup 5 tahapan. Guru hendaknya memaksimalkan setiap tahapan dalam pelaksanaan model SRSD dengan teks lagu. Tahaptahap pelaksanaan SRSD diuraikan sebagai berikut:

\section{Tahap Pengetahuan Latar}

Pada tahap ini guru harus membantu mengembangkan dan mengaktitivasi pengetahuan latar siswa. Guru memberikan siswa lembar kertas berisi teks dari genre berbeda untuk dibaca siswa. Teks tersebut akan merangsang siswa untuk mencari tahu lebih banyak genre teks. Inilah tahapan yang disebut pengembangan pengetahuan latar. Beri waktu siswa membaca dan mengidentifikasi. Pengembangan pengetahuan latar akan membantu pengembangan kosakata. Setiap enam orang siswa akan mendapat teks yang sama. Apabila di kelas terdapat 36 siswa maka ada sepuluh teks yang sama. Tahapan ini adalah tahapan SRSD dalam cakupan penetapan target. Kemampuan siswa dalam mengolah informasi yang didapat dari sebuah teks adalah target untuk mengetahui sejauh mana kemampuan membaca siswa. Guru memberi lembar kerja untuk dikerjakan siswa. Beri waktu untuk mengerjakan selama 20 menit
a. Apakah teks tersebut memuat cerita atau berita?
b. Apakah teks tersebut memuat cerita atau berita yang menarik?
c. Apa yang menarik dari cerita atau berita tersebut?
d. Adakah bahasa yang sulit dimengerti?

\section{Tahap Pembahasan}

Tahapan ini adalah lingkup SRSD pemantauan diri. Tahap ini dapat mengeksplorasi kemampuan menulis dan self-regulatory yang dimiliki siswa guna memantau kesiapan siswa dalam menulis. Guru memberikan hasil dari pertanyaan yang diajukan pada tahap pertama. Jawaban pertanyaan pada tahap ini pertama dapat menjadi simpulan terhadap kemampuan siswa dalam menalar bahan bacaan. Tunjukkan bahwa kepercayaan diri siswa terbentuk dengan baik. Hal ini akan membentuk karakter siswa. Tahap ini dilakukan setelah siswa membaca teks yang diberikan guru. Bahaslah hasil jawaban siswa dengan cara meminta salah satu siswa mempresentasikan hasil jawaban. Pilih secara acak dari sepuluh teks yang dikerjakan siswa atau tawarkan pada siswa yang siap untuk membacakan hasil pekerjaannya. Waktu presentasi setiap siswa 2 menit. Apa pendapat siswa terhadap teks yang diberikan. Tahap ini dapat memberi bahan masukan pada guru, mengenai tingkat ketercapaian siswa dalam mengidentifikasi bahan bacaan.

\section{Tahap Memberi Contoh}

Pada tahapan ini, Guru memberi contoh teks cerpen yang dikembangkan dari teks lagu. Siswa membaca dan mencermati teks lagu dan teks cerpen dan melihat kesesuaian isi teks cerpen dengan teks lagu. Siswa dapat berdiskusi tentang isi teks. Untuk tahap awal tidak ada salahnya tulisan-tulisan yang dibaca dijadikan model penulisan sebelum menemukan jati diri sendiri. Tulisan yang dibaca dapat menjadi stimulus siswa untuk belajar berbagai hal dalam menulis. Pada tahap ini guru membentuk kelompok diskusi. Setiap kelompok terdiri dari tiga orang siswa. Siswa mendiskusikan isi cerpen, ciri cerpen, dan kaidah kebahasaan cerpen. 


\section{Tugas Mandiri}

Tahap SRSD ini adalah pembelajaran diri dengan menugaskan siswa secara mandiri. Siapkan lima teks lagu dan mintalah siswa untuk mengembangkannya dalam bentuk teks cerpen. Tahap ini bisa dengan memperdengarkan lagu pada siswa sehingga siswa lebih mendalami isi teks lagu.

\section{Publikasi}

Penggunaan media sosial menjadi salah satu media publikasi yang baik untuk karyasiswa. Guru membuat blog bisa juga dalam website sekolah yang khusus untuk memuat sepuluh karya siswa terbaik. Siapkan penghargaan untuk karya siswa yang terbaik. Guru dapat menugaskan siswa untuk membacakan karya siswa pada kegiatan pembinaan di lapangan upacara. Salah satu media meningkatkan literasi siswa dengan publikasi langsung pada siswa.

Lagu menurut KBBI adalah ragam suara yang bersirama (KBBI, 771). Sebuah Teks lagu biasanya memuat sebuah pesan pada pendengar lagu. Teks lagu memuat pesan yang ingin disampaikan penulis pada pendengar lagunya. Sebuah teks lagu dapat mewakili perasaan penulis atau pengalaman yang pernah dialami penulis maupun pendengar lagu. Teks lagu dapat menjadi sumber inspirasi dalam menulis cerpen. Isi dari teks lagu dapat menjadi sebuah alur cerita.

\section{Metode}

Penelitian ini penulis mrnggunakan metode penelitian adalah metode deskriptif dengan menggunakan teknik-teknik pengumpulan data yang akan dianalisis. Metode deskriptif adalah metode yang menekankan pada penyelesaian masalah yang nyata. Pada tahap akhir penelitian ditarik kesimpulankesimpulan yang didasarkan pada data hasil penelitian (Lie, 2002).

Penelitian dilakukan di SMP Negeri 266 Jakarta Utara yang beralamat di Jalan Cilincing Bhakti VI No. 29 Cilincing Jakarta Utara. SMP Negeri 266 menjadi tempat penelitian karena peneliti mengajar di sekolah ini sejak tahun 1998. Subjek penelitian adalah siswa kelas IX D yang berjumlah 36 siswa yang terdiri dari 16 siswa laki -laki dan 20 siswa perempuan. Mata pelajaran yang menjadi sasaran penelitian adalah mata pelajaran bahasa Indonesia khususnya pada materi menulis cerpen.

Teknik pengumpulan data yang digunakan, yaitu teknik observasi digunakan secara langsung dalam kegiatan pembelajaran melalui pengamatan terhadap sikap dan minat siswa dalam menulis. Teknik tes diguanakan peneliti dengan mengadakan tes menulis cerpen menggunakan teks lagu sebagai media).

\section{Hasil dan Diskusi}

Siswa yang dijadikan subjek penelitian adalah siswa kelas IX E. Siswa di kelas ini berjumlah 36 orang. Kondisi awal pembelajaran menulis cerpen ini terekam data sebagai berikut: (1) Masih rendahnya kemampuan menulis cerpen siswa, (2) Masih tingginya hambatan/kendala yang dihadapi siswa dalam cerpen, (3) Guru belum menerapkan model pembelajaran yang inovatif secara optimal, (4) Menulis belum dijadikan kebiasaan siswa, (5)Lingkungan kelas belum kondusif untuk melakukan kegiatan menulis.

Berdasarkan tes awal dapat diuraikan bahwa kemampuan siswa dalam menulis cerpen, ternyata hanya 3 orang siswa yang mencapai ketuntasan minimal 75 atau $13.8 \%$ dari 36 siswa. Nilai terendah dari tes awal ini adalah 44 dan nilai tertinggi 80. Rata-rata kelas untuk cerpen adalah 65,8, sehingga perlu dilakukan perlakuan baru dengan metode dan strategi pembelajaran yang dapat memperbaiki kemampuan menulis cerpen siswa kelas dengan metode dan perlakuan yang tepat sehingga didapatkan tujuan pembelajaran menulis cerpen.

Siswa belum dapat mengembangkan tema dalam menulis cerpen rata-rata perolehan pada aspek ini adalah 67,2 yang artinya masih jauh dari kriteria ketuntasan minimal. Siswa juga masih belum mampu Kemampuan dalam mnegembangkan alur/plot dengan baik, rata-rata dalam aspek ini adalah 67,8. Aspek ketiga yaitu Kemampuan dalam menggambarkan latar atau setting siswa memperoleh nilai rata-rata kelas 62,2. untuk aspek keempat yaitu sudut pandang rata-rata nilai yang diperoleh siswa 64,4 dan rata-rata nilai siswa dalam penokohan serta perwatakan 67,8. Untuk itu dengan menggunakan sebuah strategi SRSD diharapkan siswa meningkat kemampuan menulis cerpen.

Motivasi untuk mulai menulis dapat bersumber dari adanya niat dan tekad yang kuat dalam diri untuk bisa menulis dan dapat pula karena stimulus faktor eksternal, seperti karena adanya iming-iming 
hadiah, tuntutan guru, nilai yang ingin dicapai. Model SRSD yang dimodifikasi dengan media teks lagu sesuai dengan tahapan SRSD digunakan untuk pembelajaran menulis cerpen.

Setelah melakukan tes awal, peneliti juga memberikan angket tentang menulis cerpen kepada siswa kelas. Angket yang telah diisi siswa, peneliti telah mengurutkan dari yang paling tinggi ke yang paling rendah kesulitan yang dialami siswa ketika mereka menulis cerpen. Dan proses itu, dapat diketahui bahwa kesulitan dalam menulis cerpen yang dialami siswa.

Tabel 1. Data Tes Awal Menulis Cerpen

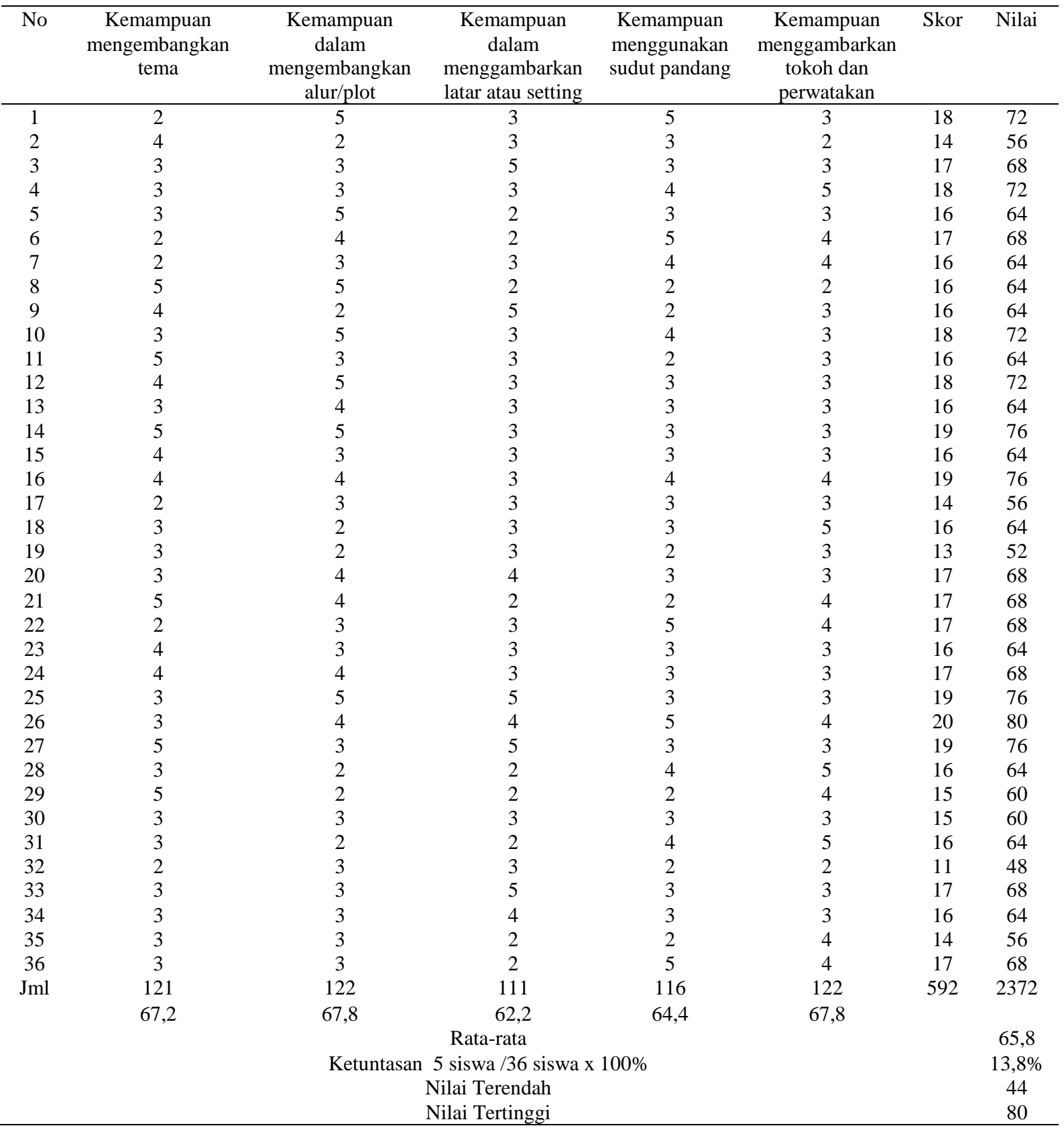

\section{Siklus I}

Berdasarkan data tersebut, peneliti memulai kegiatan pembelajaran menulis cerpen dengan sesuai dengan tahapan dalam penelitian tindakan kelas. Adapun pelaksanaan penelitian pada siklus I diuraikan berikut ini. 


\section{Perencanaan}

Guru menyusun Rencana Pelaksanaan Pembelajaran (RPP) pertemuan sebelumnya dan data awal menulis cerpen sesuai dengan strategi yang akan dilakukan di kelas yaitu strategi SRSD dan teks lagu dan menyiapkan soal untuk mengetahui kemampuan menulis cerpen secara individu.

\section{Tindakan}

Kegiatan awal menyiapkan siswa untuk konsentrasi dalam kegiatan pembelajaran; Kegiatan inti mengajak siswa untuk ikut serta dan terlibat aktif dalam pembelajaran; Kegiatan penutup meminta siswa merefleksikan pemelajaran yang telah dilakukan.

\section{Pengamatan}

Pengamatan dilakukan selama proses pembelajaran yang melibatkan guru kolaborator untuk melihat sikap siswa selama mengikuti pelajaran.

\section{Refleksi}

Data siklus I penelitian ini mencakup catatan peneliti, catatan kolaborator, dan deskripsi kemampuan menulis cerpen. Siklus I dilaksanakan selama tiga kali pertemuan adapun hasil dalam pelaksanaan siklus I diuraikan dalam data sebagai berikut.

Tabel 2. Data Menulis Cerpen Siklus I

\begin{tabular}{|c|c|c|c|c|c|c|c|}
\hline No & $\begin{array}{c}\text { Kemampuan } \\
\text { mengembangkan } \\
\text { tema }\end{array}$ & $\begin{array}{c}\text { Kemampuan } \\
\text { dalam } \\
\text { mengembangkan } \\
\text { alur/plot } \\
\end{array}$ & $\begin{array}{c}\text { Kemampuan } \\
\text { dalam } \\
\text { menggambarkan } \\
\text { latar atau setting }\end{array}$ & $\begin{array}{c}\text { Kemampuan } \\
\text { menggunakan } \\
\text { sudut pandang }\end{array}$ & $\begin{array}{c}\text { Kemampuan } \\
\text { menggambarkan } \\
\text { tokoh dan } \\
\text { perwatakan } \\
\end{array}$ & Skor & Nilai \\
\hline 1 & 2 & 5 & 4 & 2 & 3 & 16 & 64 \\
\hline 2 & 4 & 2 & 4 & 3 & 2 & 15 & 60 \\
\hline 3 & 3 & 3 & 5 & 4 & 4 & 19 & 76 \\
\hline 4 & 3 & 3 & 4 & 4 & 5 & 19 & 76 \\
\hline 5 & 3 & 5 & 3 & 4 & 4 & 19 & 76 \\
\hline 6 & 4 & 4 & 4 & 5 & 4 & 21 & 84 \\
\hline 7 & 4 & 4 & 3 & 4 & 4 & 19 & 76 \\
\hline 8 & 5 & 5 & 4 & 2 & 2 & 18 & 72 \\
\hline 9 & 4 & 2 & 5 & 2 & 3 & 16 & 64 \\
\hline 10 & 3 & 5 & 3 & 4 & 3 & 18 & 72 \\
\hline 11 & 5 & 3 & 3 & 2 & 3 & 16 & 64 \\
\hline 12 & 4 & 5 & 3 & 3 & 3 & 18 & 72 \\
\hline 13 & 4 & 4 & 4 & 4 & 4 & 20 & 80 \\
\hline 14 & 5 & 5 & 4 & 3 & 3 & 20 & 80 \\
\hline 15 & 4 & 3 & 4 & 5 & 3 & 19 & 76 \\
\hline 16 & 4 & 4 & 4 & 5 & 4 & 21 & 84 \\
\hline 17 & 2 & 3 & 3 & 3 & 3 & 14 & 56 \\
\hline 18 & 3 & 2 & 4 & 3 & 5 & 17 & 68 \\
\hline 19 & 3 & 2 & 3 & 2 & 5 & 15 & 60 \\
\hline 20 & 3 & 4 & 4 & 3 & 5 & 19 & 76 \\
\hline 21 & 5 & 4 & 4 & 2 & 4 & 19 & 76 \\
\hline 22 & 2 & 3 & 4 & 5 & 4 & 18 & 72 \\
\hline 23 & 4 & 3 & 4 & 5 & 3 & 19 & 76 \\
\hline 24 & 4 & 4 & 3 & 3 & 3 & 17 & 68 \\
\hline 25 & 3 & 5 & 5 & 3 & 3 & 19 & 76 \\
\hline 26 & 3 & 4 & 4 & 5 & 4 & 20 & 80 \\
\hline 27 & 5 & 3 & 5 & 3 & 3 & 19 & 76 \\
\hline 28 & 3 & 2 & 2 & 4 & 5 & 16 & 64 \\
\hline 29 & 5 & 2 & 2 & 2 & 4 & 15 & 60 \\
\hline 30 & 3 & 3 & 3 & 3 & 3 & 15 & 60 \\
\hline 31 & 3 & 2 & 2 & 4 & 5 & 16 & 64 \\
\hline 32 & 4 & 3 & 4 & 3 & 3 & 17 & 68 \\
\hline 33 & 3 & 3 & 5 & 3 & 3 & 17 & 68 \\
\hline 34 & 3 & 3 & 4 & 3 & 3 & 16 & 64 \\
\hline 35 & 3 & 3 & 2 & 2 & 4 & 14 & 56 \\
\hline 36 & 3 & 3 & 2 & 5 & 4 & 17 & 68 \\
\hline $\mathrm{Jml}$ & 128 & 123 & 130 & 122 & 130 & 633 & 2532 \\
\hline
\end{tabular}




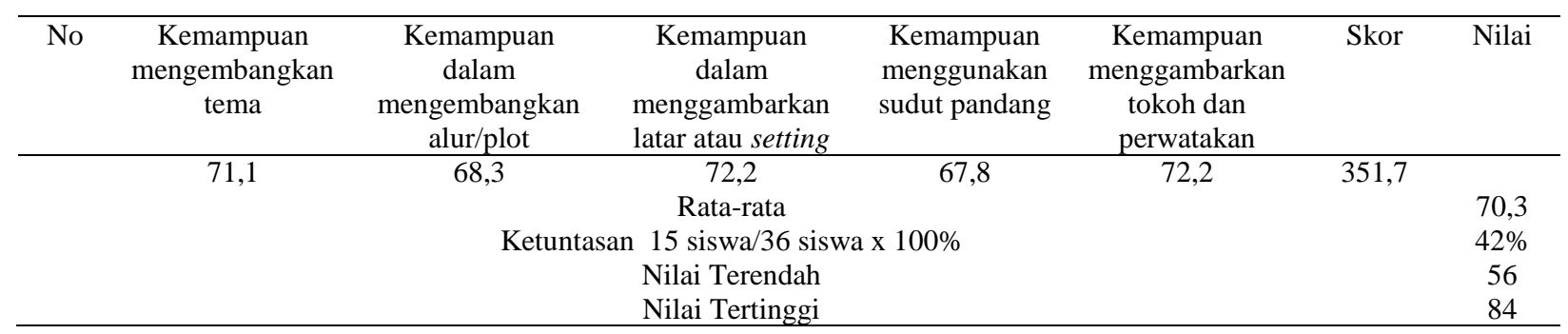

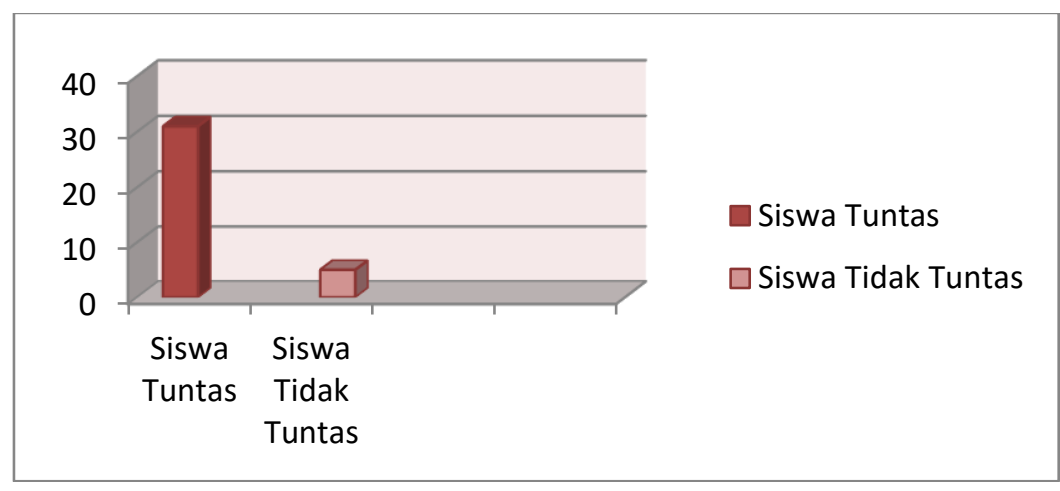

Gambar 1. Diagram pembelajaran menulis dengan $S R S D$ dan teks lagu

Berdasarkan pembahasan-pembahasan dari hasil menulis cerpen dengan model SRSD dan teks lagu siklus I didapat data sebagai berikut: (1) Nilai siswa yang telah memenuhi kriteria ketuntasan minimal yang ditetapkan oleh guru sebanyak 34 orang siswa atau hampir seluruh siswa mendapat nilai ketuntasan minimal 75; (2) Sebanyak 2 orang siswa atau 5,5\% siswa mendapatkan nilai dibawah kriteria ketuntasan minimal dengan nilai terendah yaitu 68; (3) Dilihat dari unsur-unsur intrinsik cerpen sebagian besar siswa telah mampu menggunakannya dengan baik.

Berdasarkan data pada siklus II maka penelitian tindakan kelas ini tidak perlu diadakan siklus selanjutnya karena hasil nilai yang diperoleh siswa sudah mengalami peningkatan dibandingkan pada siklus I

\section{Simpulan}

Model pembelajaran Self-Regulated Strategy Development, disingkat SRSD dapat digunakan sebagai salah satu model pembelajaran dalam menulis cerpen dengan teks syair lagu sebagai media yang memudahkan menulis cerpen. Model SRSD dapat meningkatkan kemampuan menulis siswa dengan tolak ukur adalah hasil nilai kemampuan menulis siswa yang sudah mencapai kriteria ketuntasan minimal.

Pembelajaran menulis cerpen dengan SRSD dan teks lagu, siswa berkesempatan berimajinasi dan menghasilkan sebuah karya. Semakin sering mereka menulis maka semakin baik pula hasil tulisan mereka. Model SRSD dan teks lagu dapat menjadi salah satu model dan media dalam mengajarkan menulis cerpen atau menulis teks lainnya.

\section{Ucapan Terima Kasih}

Terima kasih kepada pimpinan SMP Negeri 266 Jakarta yang telah memberikan izin kepada penulis melakukan penelitian.

\section{Daftar Rujukan}

Atmowiloto, Arswendo. Mengarang itu gampang. Jakarta: PT Gramedia. 1984.

Depdikdas. Kamus Bahasa Besar Indanesia. Jakarta: Balai Pustaka Pustaka Utama. 2007.

Irawan, Y. Menjadi penulis hebat. Jakarta: Multi Kreasi Satu Delapan. 2010.

Jingga, G. M. Yuk menulis yuuuk. Yogyakarta: Araska. 2012.

Endraswara, S. Membaca, menulis, mengajarkan sastra. Yogyakarta: Kota Kembang. 2003. 
14 Learning to write short stories with self-regulation strategy development (SRSD) and text song

Kartanegara, M. Seni mengukir kata: kiat-kiat menulis efektif kreatif. Bandung: Mizan Learning Center (MLC). 2005.

Lie, A. Cooperatif learning. Jakarta: Grasindo. 2002.

Marahimin, I. Menulis secara popular. Jakarta: Pustaka Jaya. 2005.

Mirriam, C. dan Golberg. Daripada bete, nulis aja!: panduan nulis asyik di mana saja, kapan saja, jadi penulis bekenpun bisa! (Diterjemahkan Lusy Widjaja). Bandung: Kaifa. 2006.

Musthapa. B. "Biarkan anak-anak bermain". Englishiana Journal. Edisi Februari 2008.

Nurgiyantoro, B. Penilaian dalam pengajaran bahasa dan sastra. Yogyakarta: BPFE. 2001.

Sukardi, E. Pembelajaran menulis. Jakarta: Uhamka Press. 2012.

Syaiful, A. Strategi belajar mengajar. Jakarta: PT Rineka Cipta. 2006.

Teeuw. Andreas. Membaca dan menilai sastra: kumpulan karangan. Jakarta: Gramedia. 1983.

Zabadi, F. dkk,. Bahasa Indonesia wahana pengetahuan untuk kelas IX. Jakarta: Politeknik Negeri Media Kreatif. 2013. 